\title{
Study on the Strategy of Improving the Quality of Talent Cultivation in Local Colleges and Universities
}

\author{
Wang Hongbo ${ }^{1, ~ *}$, Qian Kun ${ }^{2}$, Li Hua ${ }^{1}$, Wang Qian ${ }^{1}$ \\ ${ }^{1}$ School of Business Administration, University of Science and Technology Liaoning, Anshan, China \\ ${ }^{2}$ School of Economy and Law, University of Science and Technology Liaoning, Anshan, China
}

Email address:

whb198@126.com (Wang Hongbo), qiankun855@163.com (Qian Kun), 1h1@ustl.edu.cn (Li Hua), wangqian19028@126.com (Wang Qian)

*Corresponding author

\section{To cite this article:}

Wang Hongbo, Qian Kun, Li Hua, Wang Qian. Study on the Strategy of Improving the Quality of Talent Cultivation in Local Colleges and Universities. Science Innovation. Vol. 4, No. 1, 2016, pp. 1-6. doi: 10.11648/j.si.20160401.11

Received: January 24, 2016; Accepted: March 9, 2016; Published: April 8, 2016

\begin{abstract}
This paper studies how to improve the quality of talent cultivation in local colleges and universities in china. It first analyzes the challenges to the local colleges and universities, and puts forward the basic way to realize the sustainable development of local colleges and universities to promote employment as the goal to improve the quality of personnel training. We find that there are two barriers to the quality of local colleges and universities to improve the quality of personnel training, that is, the impact of external reputation and internal teaching mechanism. Therefore, the paper analyzes the adverse effects of reputation mechanism on local colleges and universities from the perspective of game theory, and puts forward the characteristics of local colleges and universities should promote the construction of local colleges and universities, and strengthen the reputation management. Finally, taking "econometrics" as an example, this paper analyzes the influence of curriculum teaching on the quality of talent training, and thinks that the local university teaching should be clear about the orientation of training, strengthen the course construction.
\end{abstract}

Keywords: Local Colleges and Universities, Talent Cultivation, Employment

\section{就业导向的地方高校人才培养质量提升策略研究}

\author{
王宏波 ${ }^{1, *}$, 钱坤 ${ }^{2}$, 李华 ${ }^{1}$, 王谦 ${ }^{1}$ \\ ${ }^{1}$ 工商管理学院, 辽宁科技大学, 鞍山, 中国 \\ ${ }^{2}$ 经济与法律学院, 辽宁科技大学, 鞍山, 中国
}

\section{邮箱}

whb198@126. com(王宏波), qiankun855@163.com(钱坤), 1h1@ust1.edu.cn(李华), wangqian19028@126. com(王谦)

摘要：本文研究如何提升中国地方高校的人才培养质量。文章首先分析了毕业生就业对地方院校的挑战，提出地方高 校以促进就业为目标提升人才培养质量是实现可持续发展的基本途径。我们发现，地方高校提升人才培养质量存在两 个障碍性因素, 即外部声誉影响和内部教学机制。因此, 论文从博弯论的视角分析了声誉机制对地方高校不利影响, 包括生源、师资和管理等方面, 提出地方高校应推进特色化建设, 加强声誉管理。最后, 以《计量经济学》为例分析 了课程教学对人才培养质量的影响, 提出地方高校教学应明确培养定位, 加强课程建设。

关键词：地方高校，人才培养，就业 


\section{1. 引言}

大学生就业是一个国际性的问题。随着高等教育进入 大众化时代, 中国的大学生就业问题表现的尤其突出, 已 经引起政府和和社会的广泛关注。2015年, 中国普通高校 毕业生人数已经接近 750 万, 社会上出现了 “最难就业季”

“更难就业季” 的與论 [1], 中国教育主管部门一如10多 年前一样发出做好普通高校毕业生就业工作的指导性意 见。这一形势对高校, 特别是地方高校的就业工作带来了 极大的挑战。

目前, 中国高等教育实施由规模扩张向内涵发展的战 略性转变, 更加注重提升人才培养质量。大学生就业难问 题虽然涉及社会经济发展、学校、用人单位和大学生自身 等多方面原因, 但从根本上也反映出中国高校的人才培养 存在与社会需求不相适应的问题。能够将促进人的全面发 展和满足社会需求这两个目标较好结合起来并达成, 高校 起着独特的主导作用 [2]。教育要培养什么样的人, 在不 同时代和不同社会有不同的回答。如果想切实提高高校教 学质量, 真正培养出满足社会需要的合格人才, 高校就应 当更多地听取来自社会的声音, 更多地了解 21 世纪的企业 到底需要什么样的人才 [3]。大学的人才培养应以就业为 导向, 积极探索人才培养方案的改革, 切实提高人才培养 质量, 增强大学生就业竞争力。但遗憾的是, 中国人才市 场引导高等教育改革的信号功能以及高校主动适应市场 需求的机制仍不健全 [4]。

针对地方高校的特点, 探讨其如何提升人才培养质 量, 更好地适应社会需求, 从一定层面有效地解决大学 生的就业问题具有现实意义。就中国地方高校而言, 无 论是就业率还是就业质量, 其毕业生在劳动市场的竞争 力相比高水平大学和职业教育院校都有明显的差距。一 方面, 声名、影响力不如重点大学, 吸引企业主动招聘 毕业生的能力较弱; 另一方面, 毕业生的动手操作能力 与经验不如职业院校学生, 再加上不低的就业期望, 短 期内难以适应企业环境, 这就使地方高校处于一个 “峡 谷” 地带。因此, 我们认为破解地方高校毕业生就业难 题的基本出路应是以企业需求为导向提升人才培养质量, 本文在第二部分描述其必要性。而地方高校可供选择的 主要策略则源于前述两个原因, 其一是对外加强声誉管 理, 本文从博亦论的角度予以分析; 其二是对内改善课 程的布置与教学效果, 本文以《计量经济学》为例予以 分析。

\section{2. 人才培养、就业和企业需求}

地方高校提升人才质量的首要问题是明确人才培养 的目标定位, 只有明确人才培养的基本方向, 才能恰当地 寻找人才培养的路径, 才能有利于促进就业。从就业市场 与培养过程的反馈环路来看, 高校人才培养的目标定位应 是培养企业需要的人才, 如图1。

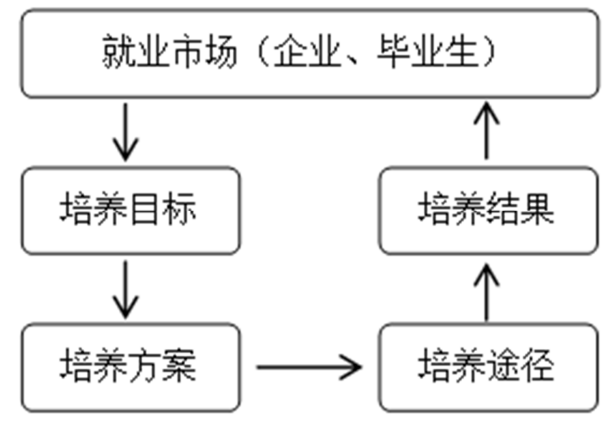

图1 就业反馈与培养过程。

\section{1. 就业与企业需求}

人才培养质量, 主要有两种评价尺度。一种是学校内 部的评价尺度, 另一种是学校外部的评价尺度, 即社会的 评价尺度。社会对高等学校人才培养质量的评价, 主要是 以高等教育的外显质量特征即高等学校毕业生的质量作 为评价依据, 而对高等学校内部的教育教学活动不是特别 的关注; 社会对毕业生质量的整体评价, 主要是评价毕业 生群体能否很好地适应市场的需求, 满足众多企业的用人 需要。

曾在苹果、SGI、微软和Google等多家IT公司担当要 职的中国著名企业家李开复 (Kai-Fu Lee) [3]认为, 创 办大学的目的或价值不在于获得了多少名和利, 而在于是 否培养出了真正对社会有用的人才, 是否获得了真正能推 动社会发展、进步的科研成果。从这个意义上看, 大学能 否通过人才培养、科研成果转化等方式让自己的 “客户” 满意, 这是大学能否真正实现自身价值的一个重要指标。 如果不能充分聆听企业对人才的需求, 高校就很难担负起 向社会输送合格人才的使命。因此, 地方高校要明确自身 的人才培养目标定位就必须建立毕业生信息反馈机制, 倾 听企业的需求。面对瞬息万变的市场经济, 学校的反应相 对滞后一些, 使得高校在专业设置上有失平衡, 教学内容 与教学方法陈旧, 培养出的许多大学生的素质和能力不适 应市场的需要。这是当前大学生就业困难的一个主要原因。

\section{2. 人才培养与企业需求}

21 世纪，企业的发展模式在不断调整，中国的经济结 构和经济增长方式也在发生根本转变。相应地, 企业的人 才需求也在不断发展变化, 对人才培养质量提出更高的要 求。现代企业对员工的基本的能力需求结构如图2所示。 (1)创新意识与能力。创新首先表现为有一个好的想法。企 业的发展离不开员工的创新意识。创新意识是创造能力的 意识前提。(2)沟通与表达能力。即将一个好的想法表达出 来, 获得上下级支持的能力。企业招聘人才希望员工更好 的融入企业这个团队以及为顾客服务, 这就需要具有良好 的沟通能力, 这不但需要智商, 更需要的是情商。(3)实践 能力。即将一个好的想法付诸实际的能力。学历只和一个 人获得的知识多少有关, 而实践能力与自我智慧的发现、 掌握和运用有关。一个空有学历而没有实践能力的人在社 
会中是不会被轻易接受的。另外, 现代经济中的企业还需 要有全球观念的人才和高素质复合型人才。

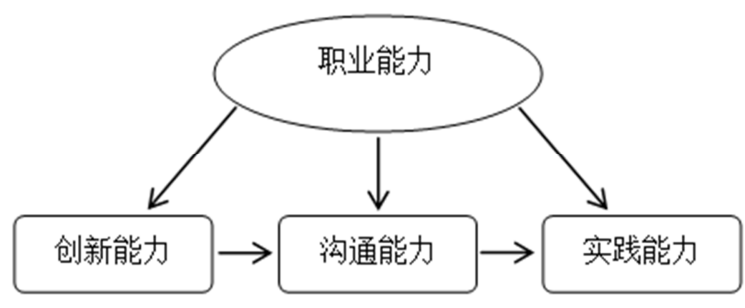

图2 职业能力结构。

\section{3. 就业、质量与大学声誉：基于博亦论的视角}

大学声誉是在长期办学过程中自然形成的知名度与 美誉度, 是社会各界对大学的学术水平、办学特色、毕业 生就业状况、校友的社会影响、生源情况等的综合评价 [5]。 声誉机制是维持社会合作的主要机制之一, 高校声誉对维 持校企合作（包括毕业生就业双向选择）具有重要意义。 博弯论最初对声誉的关注主要是集中于与声誉密切相关 的策略 “可信性” 问题上 ( “可信性” 是声誉产生的一个 重要的基础）。1982年，Kreps、Milgrom、Roberts和 Wi ison [6]在一篇经典的文献中构建了声誉模型, 该模型 通过引入非对称信息, 研究了在不完全信息重复博弯中经 济主体之间合作行为的可信性问题, 即不完全信息条件下 有限次重复博亦中的合作均衡生成机制问题, 这就是在信 息经济学、博亦论以及产业组织理论中都非常有影响的 “KMRW声誉模型” ，他们的思想被总结为 “KMRW定理” 。 KMRW定理认为, 在不完全信息的情况下, 只要博弯重复的 次数足够多, 参与人就有积极性建立一个 “合作” 声誉。

高等教育是一个信息不对称非常严重的行业。教师水 平高低、学校质量好坏, 既可以靠市场竞争基础上的声誉 机制来区别, 也可以由政府监管部门来评价。中国和美国 教育体制的最大差异就是美国的教育是靠竞争和声誉机 制，而中国是靠政府管制 [7]。

我们认为, 地方高校声誉至少影响其两个方面: 一是 对就业的直接影响。已有研究 [8] 证明大学声誉与就业率 是显著相关的。地方高校处于先天的劣势, 就业率相对不 高, 不仅在统计指标上, 更主要是在就业的质量上。二是 对师资队伍的影响。地方高校的福利水平与科研环境相对 较差, 在引进和留住高水平师资相对困难。

\section{1. 地方高校声誉与就业}

理论上, 人才培养质量应当是高校声誉的核心影响因 素, 质量越好, 声誉越好。但高校人才培养质量是难以直 接观察的, 只能通过政府和社会机构评价获取。现实情况 是，中国政府的 “985 工程” 和 “211工程” 客观上成为 中国高等教育市场明显的分割线, 加剧了教育不公平和高 校的恶性分层 [9]。部分中国企业非 “985” 和非 “211” 高校毕业生不招聘, 带有明显的歧视性, 甚至部分高校的 研究生招生中也存在。目前, 越来越多的高校也规定求职 者的最高学历, 还严格要求第一学非海归、“985”、或 “211” 不予考虑。
在声誉的形成中, 毕业生的就业情况也是重要来源 之一。美国毕业生的就业直接影响高校在全美的排名以 及招生和学生的质量, 是衡量一所大学办学成功与否的 重要指标 ${ }^{[5]}$ 。大学的声誉很大程度上还取决于校友的质 量。校友既是天然的又是主动的高校声誉的传播者。校 友向 “潜在的” 学生们直接传递着关于大学教育教学水 准的信号, 并间接地向大学其他 “潜在的” 资源提供者 们传递着关于大学学术水准的信号; 同时, 他们也有着 传播大学好的信息的强烈积极性和主动性。耶鲁大学法 学院教授Henry Hansmann [10]认为, 大学是一种 “关联 性产品”, 人们对大学的需求不取决于这所大学的需求 主要不取决于一一或者说, 至少不完全取决于收费, 而 是取决于这所大学过去培养的学生的质量、现在培养的 学生质量和预期未来可以培养的学生质量。即使你的水 平不怎样, 但是你的校友水平很高, 这样社会上就会认 为你也不会差, 你就占了优势 [4]。

美国学者戴维斯・扬（Davis Young） [11]认为, 任 何一个团体组织要取得恒久的成功, 良好声誉是至关重 要的, 声誉管理是一个价值不菲的产业。因此, 从长期 持续发展的角度看, 地方高校应致力于加强声誉管理, 使自己的声誉得到有效的提升与维护, 从而不断增强高 校的竞争力。

\section{2. 地方高校声誉与人才培养质量}

高校人才培养质量受两个基本要素影响, 即生源和师 资的质量。某个高校声誉的提升能够增加家长和学生以及 企业对该校的信心, 有助于提高生源质量, 有效提升办学 质量 [12]。良好的大学声誉还能为学校吸引更多的办学资 源、更优质的人才与师资, 有助于高校吸引人才和培养员 工的忠诚感, 稳定高校人才队伍, 同时吸引外部优秀人员 的加入, 提升竞争优势。

中国近代教育家陈鹤琴认为, 没有教不好的学生, 只 有不会教的老师。这一观点肯定了在教育活动中教师的主 导地位, 肯定了分类教学的必要性。受声誉机制影响, 地 方院校的生源质量问题不可能迅速改变, 因此教师必然要 承担提高人才培养质量的支撑作用。

地方高校教师在多大程度上能够促进人才培养质量 关键在于制度设计。在引进高水平师资时, 如果仅从薪酬 激励来看, 高校必须支付效率工资。而地方院校实施这一 策略往往受其财力所限, 难以奏效。另外, 地方高校还面 临人才流失问题, 尤其是青年教师在学历提高后往往又倾 向跳槽。因此, 地方高校必须在环境留人、感情留人等方 面下功夫。

如果能留下人, 还有个如何用人的问题。高校和教师 之间是一个标准的委托代理关系, 其中学校是委托人, 它 规定教师需要完成多重任务, 如教学、科研工作等, 并给 予教师一定的支付, 教师是代理人, 接受学校所规定的任 务后, 选择所投入的努力程度。由于学校与教师的信息不 对称, 努力程度是教师的私有信息, 当教师的行为不能被 校方完全观察时, 在自身利益最大化的驱使下, 教师可以 利用信息优势, 产生机会主义行为的动机 [13]。但由于观 察和衡量业绩的困难, 任何显性激励都不可能是完备的, 
或许, 对大学教授来说, 比较工资和职称更重要的激励机 制是声誉机制, 也就是在学生和同行中的口碑 [8]。市场 解决信息不对称的最重要的机制是声誉机制, 而声誉机制 在市场上发挥作用的重要形式是建立品牌。在中国, 品牌 的建立主要依赖政府评价, 如政府评选的教学名师、精品 课程、优秀团队等。除此之外, 地方高校树立品牌的基本 途径就是集中校内外主要资源进行特色化建设。

\section{3. 一个政策的囚徒困境}

值得关注的是，大多数地方高校目前办学中的 “宽进 严出” 政策是失效的。由于政府基本教育经费的投入与学 生人数直接关联, 导致地方院校迫于招生压力, 不断降低 招生标准, 扩大招生规模, 但很少有高校愿意承担严格管 理带来的短期损失, “严把出口关” 的实际执行效果十分 不好。失效的 “宽进严出” 政策使地方高校教师在人才培 养过程中处于囚徒困境。如表1所示。

表1 教与学的囚徒困境。

\begin{tabular}{llll}
\hline & \multicolumn{3}{c}{ 教师教学 } \\
\cline { 3 - 4 } & & 积极 & 应付 \\
\hline \multirow{2}{*}{ 学生学习 } & 积极 & 4,3 & 2,5 \\
& 应付 & 6,1 & 3,2 \\
\hline
\end{tabular}

假设在一门课程教学中, 一名学生以考试成绩及格为 目标 (可以理解为是 “宽进” 的结果), 但考试成绩较差, 任课教师为保证及格率使同等程度的学生都通过了考试 (可以理解为不能 “严出” 的结果)。在教与学的博亦中, 学生和教师都有两个策略选择: 积极和应付。如表 1 所示 支付结果, 博弯的纳什均衡是（应付, 应付), 即学生不 会积极学习, 教师也不会积极教学。出现这样的结果的关 键在于假设: (1)学生仅以通过考试为目标。如果应付般地 学习就能通过考试, 学生的最优策略就是应付 (6>4和 $3>2$ ), 其选择与教师积极程度无关; (2)而教师的目标只是保证及 格率。如果马马虎虎地教学, 学生也能通过考试, 教师的 最优策略也是应付 $(5>3$ 和 $2>1)$, 其行为选择则与学生学 习态度无关。通过表 1 还可以看出, 在教师积极教学情况 下的学生收益相对更大 $(4>2$ 和 $6>3)$, 也就是说, 学生无 论自身是否积极都希望敬业的教师授课; 而在学生积极学 习情况下教师收益也相对更大（3>1和5>2），即教师都希 望教授努力的学生。但行为主体的出发点已经注定了不良 的行为结果一一学生应付学习, 教师应付教学, 人才培养 质量只能越来越差。地方高校在人才培养过程中应从实际 管理效果上避免教师与学生陷入囚徒困境。

\section{4. 人才培养质量与课程建设: 以《计量经济学》 为例}

美国教育学家克伯屈（William Heard Kilpatrick） [14]认为, 教育即成长, 完美的生长应包括知、能、愿三 个方面。知指知识和眼光; 能指技能和方法; 愿指态度和 习惯”。课程是教育思想、教育理论转化为教育实践的中 介或桥梁, 教育实践常以课程为轴心展开, 教育改革也常 以课程改革为突破口而进行 [15]。在以就业为导向的人才
培养策略中, 从专业培养方案到课程设置, 都应该以体现 出 “三位一体” （如图3）的质量观, 即在课程设置与教 学中必须有明确的倾向: 这门课程传授什么知识、训练什 么能力和教化什么素质。不同类型、不同性质的课程, 在 目标设置上又各有侧重、相互补充, 以系统促进学生的发 展。比如核心课程的目标设置, 主要是为了向学生传授所 在学科的核心知识、原理与技术; 选修课的设置, 目的是 对学科基本知识进行有益的补充, 以推动学生探索前沿研 究方向, 寻找新的研究问题, 训练学生的分析、沟通能力 和批判性思维等; 跨学科课程的设置旨在拓宽学生的知识 面, 扩大学生的学科视野, 使其打好学科交叉基础, 训练 其跨学科、多学科的研究思维 [16]。

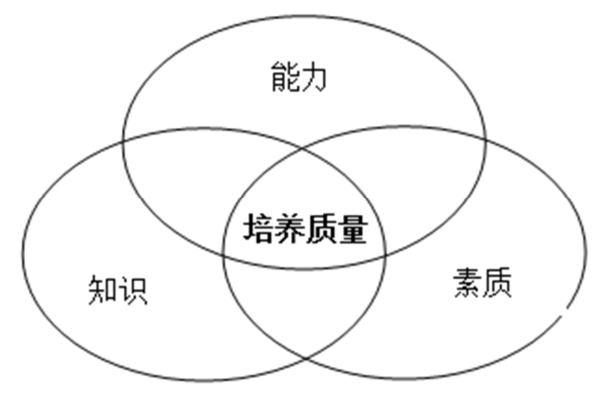

图3 课程质量结构。

诺贝尔经济学奖获得者克莱因 (L. R. Klein) 曾指出, 计量经济学已经在经济学科中居于最重要的地位, 在大多 数大学和学院中, 计量经济学的讲授已经成为经济学课程 表中最有权威的一部分; 而萨缪尔森（P. Samue1son）也 指出, 第二次世界大战之后的经济学是计量经济学的时代 [17]。可见, 计量经济学作为一门学科将在未来发挥越来 越重要的作用。本文以某一地方高校的工商管理学科的 《计量经济学》课程为例, 具体说明如何在课程教学实践 质量观，提升人才培养质量。如表2。

表2《计量经济学》课程与专业人才培养。

\begin{tabular}{|c|c|c|}
\hline 知识 & 能力 & 素质 \\
\hline$\square$ 人文社科知识政策 & $\square$ 学习与发展能力 & 、独立性 \\
\hline$\square$ 法规和惯例知识 & 】信息获取与表达能力 & $\square$ 冒险精神 \\
\hline 】数理、计算机知识 & $\square$ 才队协作能力 & $\square$ 竞争意识 \\
\hline$\square$ 外语基础知识 & $\square$ 就业创业能力 & 】合作意识 \\
\hline 专业理论与实务知识 & 】专业胜任能力 & 『批判性 \\
\hline 口专业外经济管理知识 & 】科学研究与创新能力 & $\square$ 健全的人格 \\
\hline 口工程技术与社会责任 & 口管理决策能力 & $\square$ 社会责任感 \\
\hline
\end{tabular}

\section{1 . 传授知识}

计量经济学课程的讲授能够帮助学生全面系统地学 习和把握有关计量经济学的基础理论与基础知识。例如, 对经典单方程模型 (一元线性回归模型及多元线性回归模 型）、联立方程、时间序列、面板数据等相关领域有更为 直观且深刻的理解, 并且对模型构建过程中出现的异方差 性、自相关性、多重共线性等假设检验进行相关处理, 进 而运用所构建模型对未来一定期间内的经济现象进行合 理预测。本课程还促进学生掌握一定的数理基础知识, 以 及更多的计算机知识。 
在本科或研究生阶段开设《计量经济学》课程, 学生 通过实证研究进一步加深了对专业领域基本原理和基本 方法的掌握。同时, 学生可以结合自己研究方向, 为发表 学术论文做准备。

\section{2. 训练能力}

目前, 中国的一些重要期刊较为重视实证分析。据统 计, 以计量经济学模型方法作为主要分析方法的论文占全 部论文的比例超过 $50 \%$, 而且研究对象遍及经济的各个领 域, 所应用的模型方法遍及计量经济学的各个分支 [18]。 计量经济学课程一般要求学生应用课堂所学到的计 量方法, 选取社会经济中相关热点问题进行数据处理。这 样既能够锻炼学生发现问题、分析问题的能力, 又能够借 助于Eviews、SPSS等软件对所学理论进行相关检验, 构建 最终的模型表达式, 以达到解决问题的目的, 强化了同学 们的科学思维能力, 检验了课程教授的效果。在计量分析 中, 学生需要通过广泛的渠道收集与获取信息, 并能够对 信息的识别和处理, 予以清晰的说明, 从而训练了他们信 息获取与表达能力。

在对现实社会经济问题进行分析评价时, 运用定性分 析与定量分析相结合的方法, 其实质就是理论联系实际的 衍生。对问题的研究如果只是定性评论, 将缺乏说服力度, 通过计量经济学中的相关检验, 对定性问题进行量化处理, 将得到更为直观的理解。而在此过程中, 学生的科研思维 能力也将得到最大锻炼, 进而促进专业能力成长。

\section{3. 教化素质}

在教学实践中, 计量经济学课程改革提倡自主创新的 学习形式。课程讲授过程中, 以教师引导和学生自学为主。 这样既能够使学生对计量相关理论有全面把握, 又能够养 成学生独立思考、研究问题的态度和习惯。课程通过小组 讨论等形式增强学生间合作意识, 在研讨中能够相互激发 灵感。

在计量分析中, 实证检验的结果可能与预期不同, 因 此就要求学生能够批判性分析问题, 敢于怀疑理论、敢于 怀疑数据, 勇于尝试新方法, 能够不解寻找问题的根源。 重要的要, 这样训练端正了学生的学术态度, 养成了好的 学术习惯, 提高了研究能力。

总之, 一门课程只有在明确地解决了上述三个问题后, 才能有效地提高教学质量, 实现人才培养目标。

\section{5. 结束语}

地方高校是一个特殊的群体, 其毕业生就业处于一个 “峡谷” 地带。基本原因是地方高校人才培养质量难以适 应企业需求。而地方高校提升人才培养必须着力解决两个 问题: 其一是外部声誉问题, 地方高校与一些研究型大学 相比, 声誉机制使地方高校在获取办学资金、生源和师资 等方面处于不利地位, 严重制约人才培养质量的提高; 其 二是内部课程教学问题, 与职业院校而言, 地方高校的专 业设置与课程教学存在定位不明确, 管理不到位等问题。
因此, 地方高校的可持续发展必须以提高质量为主核心, 而提高质量需要加强声誉管理和课程建设。

\section{致谢}

本文为辽宁省普通高等教育本科教学改革研究项目 《财务管理专业特色发展的比较研究与实践》 (UPRP20140384); 辽宁科技大学研究生教育创新计划项 目《计量经济学》（2013YJSCX03）; 辽宁科技大学面向 “十三・五” 标志性成果教学改革项目《就业导向的高校 管理类人才培养质量提升策略研究》的阶段性成果之一。

\section{参考文献}

[1] 荆德刚. 新常态视角下的大学生就业形势与任务 [J]. 中国 高教研究, 2015, 12: 37-40。

[2] 施炜. 产业转型升级下高校提升大学生就业能力模型研究 [J]. 江苏高教, 2016, 1: 108-110。

[3] 李开复. 致中国高校的一封信: 请培养 21 世纪需要的人才 [Z]. (2006-11-06), http://news. xinhuanet. com/oversea s/2006-11/06/content_5296504. htm。

[4] 马廷奇. 利益相关者与大学生就业体制变革 $[J]$. 高等工程 教育研究, 2015, 1: 51-56。

[5] 李蕴, 段婕. 高校声誉机制的经济管理学分析 [J]. 兰州大学 学报(社会科学版), 2009, 37 (2): 129-133。

[6] D. Kreps, R. Milgrom, J. Roberts and R. Wilson. Rational Cooperation in the Finitely Tepeated Prisoners' Dilemma[J]. Journal of Economic Theory. 1982, 27: 245-252.

[7] 张维迎. 博亦与社会 [M]. 北京: 北京大学出版社. 2013: 198。

[8] 王丽君, 张志红. 大学声誉与大学生就业率的关系研究及启 示 $[\mathrm{J}]$.科技信息, 2011，1：155-157。

[9] 易连云, 赵国栋, 冊改霞. 高校教师聘任的 “出身论” 现象 研究——对百所 “985”、“211” 院校的调查 $[\mathrm{J}]$. 重庆大 学学报 (社会科学版), 2013, 19(5): 113-117。

[10] Henry Hansmann. Higher Education as An Associative Good. Yale Law and Economics Working Paper No. 231; Yale ICF Working Paper No. 99-15.

[11] 戴维斯 -扬. 创建和维护企业的良好声誉 [M]. 赖月珍, 译. 上海：上海人民出版社，1997：162。

[12] 舒颖岗. 大学声誉培育与高水平大学建设 $[\mathrm{J}]$, 国家教育行 政学院学报, 2011, 12: 21-25。

[13] 李越恒. 基于委托代理的高校教师学术寻租行为的博亦分 析 [J].系统工程, 2008, 26 (11): 85-89。

[14] 王沛民, 顾建民, 刘伟民. 工程教育基础 [M]. 杭州: 浙江大 学出版社, 1994: 59-64。 
[15] 华芳英. 论系统视野下开放大学的课程建设 [J]. 远程教育 杂志, 2014，3: 91-96。

[16] 包水梅. 美国学术型博士生课程建设的特征与路径研究 [J]. 高校教育管理, 2016, 10 (1) : 116-123。
[17] 李子奈. 关于计量经济学课程教学内容的创新与思考 $[\mathrm{J}]$, 中国大学教学, 2010, 1: 18-22。

[18] 李子奈. 计量经济学应用研究的总体回归模型设定 $[J]$. 经 济研究, 2008, 8: 136-143。 